\title{
The Association between Communication, Customer Relationship Management and Organisational Performance: Evidence from the Saudi Arabia Hospitals
}

\author{
Yaser Salman Alsharari \\ Director of the General Maiqua Hospital \\ Al-Jawf, Ministry of Health, Saudi Arabia \\ and
}

School of Business and Management (SBM), College of Business (COB)

Universiti Utara Malaysia (UUM), Malaysia

E-mail:m.m.w@hotmail.com

Fadzil Shah bin Aziz

School of Business and Management (SBM), College of Business (COB)

Universiti Utara Malaysia (UUM), Malaysia

Che Azlan Bin Taib

School of Business and Management (SBM), College of Business (COB)

Universiti Utara Malaysia (UUM), Malaysia

\section{Rushami Zien Yusoff}

School of Business and Management (SBM), College of Business (COB)

Universiti Utara Malaysia (UUM), Malaysia

Received: May 23, 2017

doi:10.5296/jmr.v9i4.11776
Accepted: August 7, 2017

Published: October 1, 2017

URL: https://doi.org/10.5296/jmr.v9i4.11776 


\section{Abstract}

This research aims to examine the influence of the communication, customer relationship management on organisational performance among Saudi Arabia Hospitals. Furthermore, to exam the study model, the survey questionnaire was used to collect data 154 hospitals randomly chosen from 259 government hospitals in Saudi Arabia. For data analysis, the Partial Least Squares (PLS) structural equation modeling was used. In addition, this study found a positive and significant association between communication, customer relationship management, and organisational performance. Ultimately, this study offers some limitations and suggestions for future researchers.

Keywords: Communication, Customer Relationship Management Organisational Performance and Saudi Arabia. 


\section{Introduction}

Service quality has gained a great deal of importance topic for practitioners and researchers over the past two decades. Much of the academic interest in service quality has been directed toward service quality measurement (Bitner 1990, Bolton and Drew 1991a; Parasuraman et al., 1994). These authors focused on the identification of five dimensions of service quality: reliability, responsiveness, assurance, tangibles and empathy. Reliability is the ability of a hospital to perform the promised service accurately. Responsiveness is the willingness to help patients (customers) and provide them with prompt services. Assurance is the knowledge and courtesy of staff and their ability to convey trust and confidence. Empathy is the caring, individualised attention provided to the patient. Tangibles are the appearance of physical facilities, equipment personnel and communications material.

Several studies conducted on hospital performance in developing countries attributed a poor hospital performance to the lack of resources available in these hospitals (Farid, 2008). However, other studies argued that higher level of performance can be provided even with severely limited resources. For example, a cross-sectional study of Jamaican hospitals found that a better process was linked significantly to high quality health services while a study on Indonesian hospitals found that $60 \%$ of all patients' deaths were attributed to poor process and only 37\% to funding difficulties (Supratiko et al., 2002). More importantly, even if the case of lower levels of performance in the public hospitals is attributed to the lack of funding, this should not be the case in Saudi Arabia taking into account the huge budget allocated for the healthcare sector represented by the Ministry of Health. Apart from that, Saudi Arabia is one of the wealthiest and quickest developing nations in the Middle East and is also the world's biggest producer and exporter of oil, which constitutes the significant segment of the nation's incomes (Ministry of Finance report, 2010). Thus, if public hospitals in Saudi Arabia are characterised by poor organisational performance, this means that some other non-financial factors could be the explanation to such performance.

The government of Saudi Arabia has been putting enormous efforts to reform the Saudi public hospitals and solid advancements have taken place. In this context, Almalki, Fitzgerald \& Clark (2011) assure that health care services in Saudi Arabia have been given a high priority by the Saudi government. The authors go on to say that during the past few decades, health and health services improved greatly in terms of quantity and quality. In addressing the advancements that took place in the Saudi heath care system and the efforts the Saudi government put in to achieve these advancements, Gallagher (2002) argued that "Although many nations have seen sizable growth in their health care systems, probably no other nation (other than Saudi Arabia) of large geographic expanse and population has, in comparable time, achieved so much on a broad national scale, with a relatively high level of care made available to virtually all segments of the population" (p. 182). Almalki et al. (2011) addressed the attempts that have been done to meet the challenges of the Saudi health care system and improve the quality of health care services; he states that the Ministry of Health (MOH) has set a national strategy for health care services. This strategy, approved by the Council of Ministers in April 2009, focuses on diversifying funding sources, developing information systems, developing the human workforce; activating the supervision and monitoring role of 
the $\mathrm{MOH}$ over health services, encouraging the private sector to take its position in providing health services, improving the quality of preventive, curative and rehabilitative care, and distributing health care services equally to all regions.

Based on the above discussion, this study aims to fill the gap up in the extant literature in the emerging countries, particularly SaudiArabia by examining the relationship between communication, customer relationship management, and organisational performance among the Saudi Arabian Hospitals in order to enhance the knowledge and give a clear picture about the current situation.

\section{Literature Review and Hypotheses Development}

\subsection{Communication and Organisational Performance}

Healthcare organisations and their employees normally work in complex, demanding and dynamic environments and this is why effective communication among the team members working in the different departments of hospitals is of paramount importance for the safe delivery of health care which would in turn that better healthcare service quality is achieved (Canadian Patient Safety Institute, 2011). In this context, Gawande Zinner, Studdert and Brennan (2003) argue that communication breakdowns and teamwork failures have been identified as key contributing factors in the healthcare service quality in and turn the performance of healthcare providers. In support of this view, Leonard, Graham, and Bonacum (2004) state that effective communication in the healthcare organisations has been cited as essential for achieving high reliability and quality systems in which a "culture of safety" is fulfilled in hospitals.

Furthermore and in terms of the importance of the construct of communication in the healthcare sector, Payne (2006) argues that communication is the most important aspect of the service delivery as communication among the employees from different departments and also between these employees and patients is vital to delivering service satisfaction because when hospital staff takes the time to answer questions of concern to patients, it can alleviate many feelings of uncertainty (Payne, 2006). Furthermore, when the medical tests and the nature of the treatment are clearly explained, it can alleviate their sense of vulnerability (Friedman \& Kelman, 2007). This component of service is valued highly as reflected in the in-depth interviews and influences patient satisfaction levels significantly (Pickton \& Broderick, 2001). In addition, employees working in hospitals whether hospital managers, heads of departments, doctors, nurses, admin personal seem to agree that communication among employees from different departments lead to faster and more efficient services which will in turn increase the satisfaction of patients (Friedman \& Kelman, 2007).

Payne (2006) argues that communication challenges have a negative impact on: access to treatment, participation in preventive measures, ability to obtain consent, ability for health professionals to meet their ethical obligations, quality of care, including, hospital admissions, diagnostic testing, medical errors, patient follow-up, and patient safety. According to the Institute of Medicine of the National Academies (2004), communication challenges contribute to reduced quality, adverse health outcomes, and health disparities. In 
this context, Irving and Dickson (2004) argue that there is evidence that communication challenges may result in increased use of expensive diagnostic tests, increased use of emergency services and decreased use of primary care services, and poor or no patient follow-up when such follow-up is indicated.

Alharbi (2014) argues that effective communication among workplace colleagues within a hospital makes the tasks easier as the employees work together towards a common shared task; thus, one individual is not solely responsible for any job. Furthermore, the researcher further elaborates that cooperation within the hospital would allow for more efficient treatment and specialized attention for the patients. Having good employee relations also mean that employees do not compete for recognition or credit, rather they all work together towards the service for and satisfaction of the patients. If these qualities of the communication and teamwork within a hospital are met, it is more likely that the quality of the service provided by the hospital is perceived by the employees as more positive. Thus and based on these arguments from the literature, the following hypothesis is proposed for further examination in this study.

Hypothesis 1: Communication among healthcare professionals is positively related to healthcare service quality in the Saudi public healthcare sector.

\subsection{Customer Relationship Management and Organisational Performance}

It has been mentioned earlier that healthcare providers are striving to compete with each other in order to offer the excellent service to patients. Generally speaking, healthcare sector is one of the service industries that involves a high encounters and interaction between healthcare providers and patients and this interaction between healthcare providers and patients is recognized as a complex process (Bansal, 2004). The complexity of this interactional process can be attributed to the different needs, expectations and preferences between patient and healthcare providers. In the context of this interaction between patients and healthcare providers, customer relationship management (CRM) is viewed as a strategy for organization to manage and maintain the relationship with customers as well as keeping the entire of customer's record. Record of all contact and patients information is really important to be keep in ensuring healthcare providers can perform the treatment accurately (Habidin et al., 2015).

A number of previous researchers explored the literature on CRM and the findings of these studies provided various definitions for CRM. For example and in order to provide a comprehensive general definition for CRM that would fit any organisation, Zablah et al. (2004) defined the construct as a process, strategy, capability, or as a technological tool. However and in the healthcare sector, CRM is seen as a strategy to maintain and retain the profitable customers in long term relationship between healthcare providers and patients. Apart from that, CRM can be utilised by healthcare organisation in order to find the right customer together with creating customer loyalty which is regarded as a very strong determinant of organisational performance (Zineldin, 2006a). All in all, one could conclude that the construct of CRM strategy is an important tool for organizations in general and those operating in the healthcare sector in particular to maintain a healthy relationship with 
customers (patients) and to store customer information in an efficient and more systematic way.

Yina (2010) investigated healthcare providers in utilising customer relationship management as a philosophy and at the same time a strategy in building trust with their patients together with helping these patients not feeling alienated in the healthcare environment and at the same time improving the service quality and efficiency of healthcare (Cheng et al. (2008). The researcher further elaborates that now with the availability of the Web technology, CRM has the ability to provide healthcare providers with the capacity to extend services beyond its traditional and classical practices. It also provides a competitive advantage environment for a healthcare provider to achieve a complex patient care goal. The whole process of CRM has the ability to enable a healthcare provider to capture essential patient (customer) information to be utilized in an effective way particularly in integrating the patients' information in a system to promote great service and in turn customer satisfaction.

Richard and Ronald (2008) argue that among the most critical aspects in the context of healthcare management is the way the relationship between a healthcare provider and its customers (patients) is managed as this would help in creating a better mutual understanding, trust and on top of that patient involvement in decision making. Furthermore, the researchers further elaborate that a good relationship between healthcare providers and their patients would also lead to improving customers' satisfaction and in turn their loyalty taking into account the well-established link between customer satisfaction and customer loyalty and in turn organisational performance.

An example about how CRM improves the quality of life of patients and in turn the performance of hospitals was provided by Arora (2003) who states that an effective relationship between healthcare providers and their patients not only improves these patients' satisfaction, but also helps in creating effective communications between them and this would help in improving their health and health-related quality life, particularly in the management of chronic disease. The researcher further elaborates that failure in managing the relationship between healthcare providers and their patients would lead to dissatisfaction which may lead to distrust towards the whole healthcare system provided. Apart from that, negative and unmanaged relationship between healthcare providers and their patients would make these patients feel alienated during the process of treatment. This is a good relationship between a healthcare providers and their patients is believed to be critical and such relationship ought to be managed effectively to sustain the business and in turn make it perform better. Thus and based on these arguments, the following hypothesis is proposed for further examination in this study.

Hypothesis 2: Customer relationship management (CRM) is positively related to healthcare service quality in the Saudi public healthcare sector.

\section{Research Method and the Study Model}

As far as social research is concerned, it is not always ideal to include the entire population to take part in the study. A very important reason for this is that sometimes it is impossible to do 
that due to time and funding resources constraints (Cohen et al. 2000). Consequently, Cohen et al. (2000) argue that researchers should decide upon the sample size and also sampling technique that will be used prior to conducting the research. Sampling is the process through which participants are selected in a way that they will be representative for whole population from which they are taken (Gay et al., 2006). Pallant (2007) states that researchers have not reached an agreement about the sample size. However, majority of researchers tend to agree that the a larger sample is better than a small one as the latter often lead to inaccurate correlation coefficients and hence defeats the study purpose. The population of the present study included all the public hospitals in Saudi Arabia represented by the directors in these hospitals. It should be kept in mind that there are 13 directorates (provinces) in Saudi Arabia and in these provinces, there are 259 public hospitals constituting the population of the present research (Health Statistical Year Book, 2014).

In addition, this study constituted the directors of the public hospitals in Saudi Arabia. The total number of these directors is 259 directors. Based on Sekaran (2003), if the population is more than 259, a recommended sample of 154 respondents would be regarded as representative of the whole population. Thus and based on this argument, 154 directors of public hospitals in Saudi Arabia constituted the sample of this study.

The following table (Table 1) shows the measurement of the independent variable of communication.

Table 1. Measurement of Communication

\begin{tabular}{ll}
\hline No. & \multicolumn{1}{c}{ Item } \\
\hline 1. & Everyone in our hospital contributes to a team effort in serving patients. \\
2. & Hospital staff feel that they part of a team in our hospital. \\
3. & Fellow hospital staff cooperate more often than they compete. \\
4. $\quad$ We clearly are a team with a shared task - not a collection of individuals who have their own \\
5. $\quad$ Staff members within our hospital have good working relationships. \\
6. Different departments have good working relationships with the other hospital departments. \\
7. $\quad$ Medical tests and the nature of the treatment are clearly explained to patents. \\
8. Our staff respond fast and effectively to patients' inquiries and concerns. \\
9. $\quad$ No patient hospital staff deal with leaves with problems unsolved. \\
10. $\quad$ Reaching out to patients and helping them is a great thrill to our staff.
\end{tabular}

The following table (2) shows the measure of CRM utilised in this study. 
Table 2. Measurement of Customer Relationship Management

\begin{tabular}{cl}
\hline No. & \multicolumn{1}{c}{ Item } \\
\hline 1. & This hospital treats its patients with respect. \\
2. & Experiences of our patients with this company exceed their expectation. \\
3. & This hospital treats its patients as important customers. \\
4. & Our patients recommend the hospital to their friends and family. \\
5. This hospital earns the trust of our patients. \\
7. This hospital solves patients' problems efficiently. \\
8. $\quad$ Out patents identify themselves with this hospital. \\
9. This hospital offers personalized customer service. \\
10. This hospital tries to get to know the preferences, questions and suggestions of patients. \\
11. The services provided by this hospital are a good value (the benefits exceed the cost). \\
12. This hospital rewards the loyalty of its patients.
\end{tabular}

Source:Demo and Rozzett (2013)

To measure Organisational Performance, 33 items were adapted from Balance Score Card (BSC) has been used in recent studies in the Saudi public sector when the scale was utilised in Bin Omira (2014) study who attempted to examine the impact of a number of organisational factors on organisational performance in the Saudi public sector represented by a number of Saudi ministries as provided in Table 3 as follows: 
Table 3. Balance Score Card (BSC)

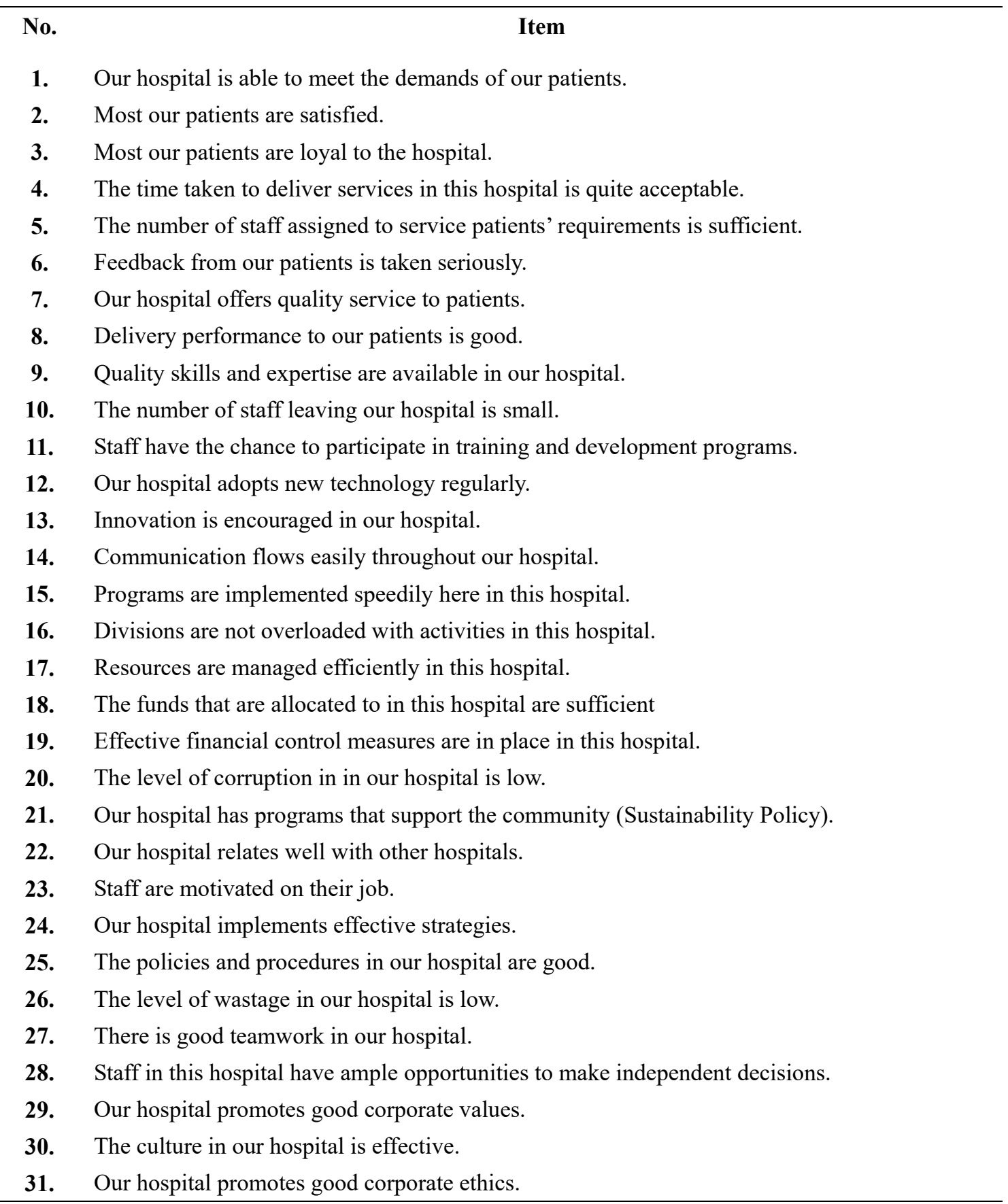

\section{Statistical Analysis and Results}

The reliability and validity of the outer model was confirmed with the help of the Partial Least Squares (PLS3), with both reliability and validity considered as initial tests prior to the testing of hypotheses. The study model comprises of communication, customer relationship management, and organisational performance. The relationships between the above variables were investigated through Chin's (1998) 2-step approach. 


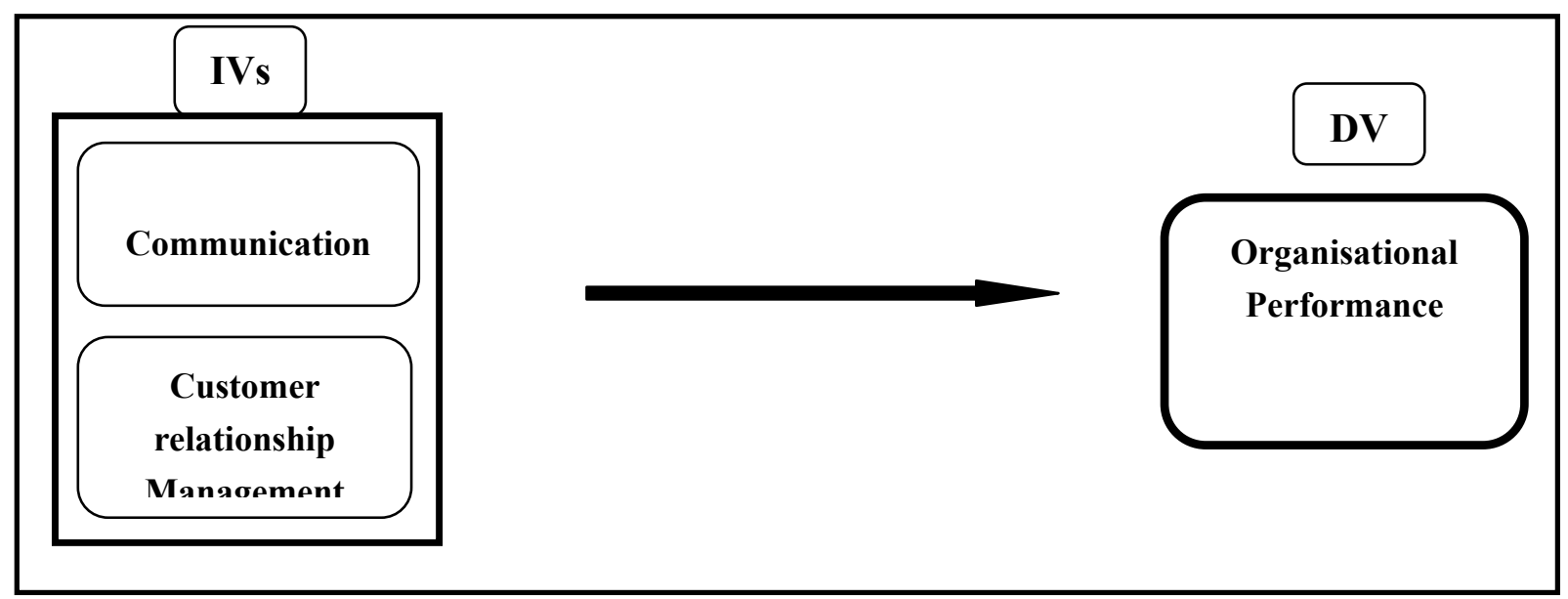

Figure 1. The Research Framework

Literature dedicated to the Structural Equation Modeling (SEM) establishes the importance of the confirmation of both validity and reliability prior to testing of hypotheses.

\subsection{The Outer Model (Measurement)}

In the following sub-sections, the constructs validity and reliability are tested prior to establishing the model's goodness of measure. Both validity and reliability was examined using content validity, discriminant validity and convergent validity as detailed in the coming sub-sections.

\subsubsection{The Content Validity}

Literature concerning multivariate analysis states that a construct's content validity is tested by comparing it with the other constructs in the model. Specifically, Chin (1998) and Hair et al. (2010) established that the factor loading reflects the constructs content validity in that items are dropped if they load higher on other constructs compared to their own. All the constructs loaded higher on their variables as presented in Table 4, indicating that the measurement model has content validity. 
Table 4. Cross Loadings of the Items

\begin{tabular}{|c|c|c|c|c|}
\hline Construct & Items & COM & CUS_REL & ORG PER \\
\hline \multirow[t]{9}{*}{ Communication } & COM1 & 0.803 & & \\
\hline & COM2 & 0.828 & & \\
\hline & COM3 & 0.881 & & \\
\hline & COM4 & 0.79 & & \\
\hline & COM5 & 0.89 & & \\
\hline & COM6 & 0.779 & & \\
\hline & COM7 & 0.836 & & \\
\hline & COM8 & 0.624 & & \\
\hline & COM9 & 0.773 & & \\
\hline \multirow[t]{12}{*}{ Customer relationship Management } & CUS_REL1 & & 0.702 & \\
\hline & CUS_REL10 & & 0.767 & \\
\hline & CUS_REL11 & & 0.708 & \\
\hline & CUS_REL12 & & 0.79 & \\
\hline & CUS_REL2 & & 0.705 & \\
\hline & CUS_REL3 & & 0.692 & \\
\hline & CUS_REL4 & & 0.811 & \\
\hline & CUS_REL5 & & 0.815 & \\
\hline & CUS_REL6 & & 0.806 & \\
\hline & CUS_REL7 & & 0.796 & \\
\hline & CUS_REL8 & & 0.778 & \\
\hline & CUS_REL9 & & 0.73 & \\
\hline \multirow[t]{7}{*}{ Organisational Performance } & ORG_PER13 & & & 0.679 \\
\hline & ORG_PER17 & & & 0.725 \\
\hline & ORG_PER20 & & & 0.662 \\
\hline & ORG_PER24 & & & 0.78 \\
\hline & ORG_PER25 & & & 0.779 \\
\hline & ORG_PER26 & & & 0.655 \\
\hline & ORG_PER27 & & & 0.732 \\
\hline
\end{tabular}




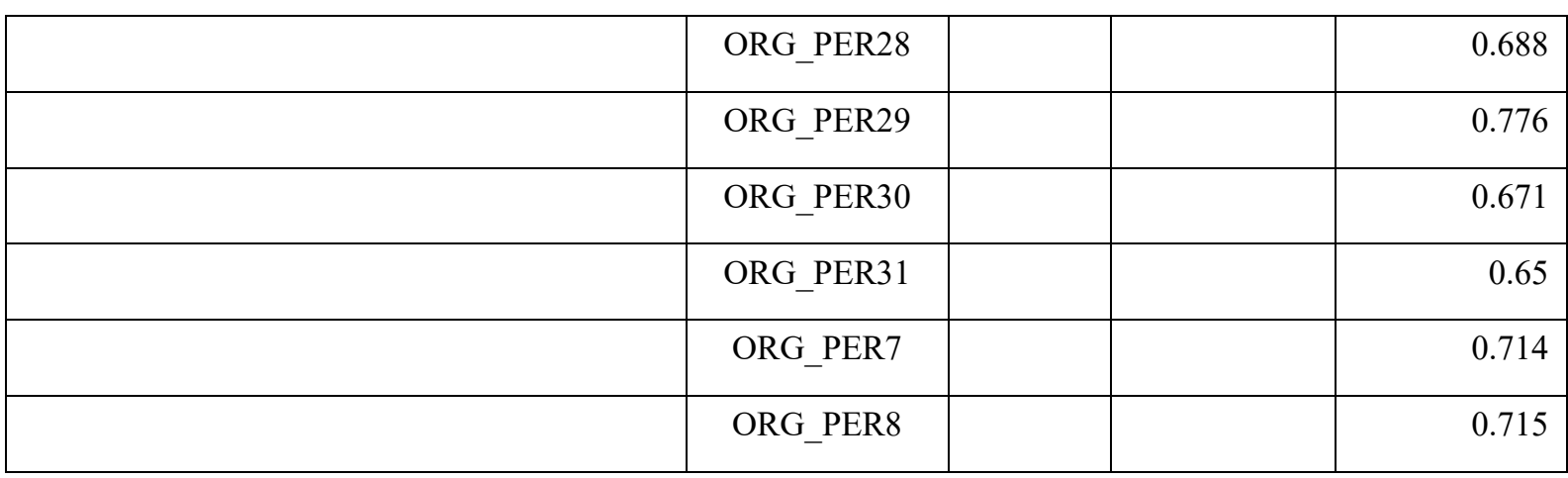

\subsubsection{The Convergent Validity}

The convergent validity refers to the level of a group of items converging to gauge a certain variable (Hair et al., 2010). In the literature dedicated to SEM, convergent validity is tested through composite reliability, loading, and average variance extracted (AVE). The items are deemed highly loaded when their loadings are at least 0.7 , AVE is at least 0.5 and composite reliability 0.7 . All these conditions are satisfied as presented in Table 5. In other words, the outer model (measurement model) has appropriate convergent validity (Bagozzi\& Yi, 1988).

Table 5. The Convergent Validity Analysis

\begin{tabular}{|c|c|c|c|c|c|}
\hline Construct & Items & Loadings & $\begin{array}{l}\text { Cronbach's } \\
\text { Alpha }\end{array}$ & $\begin{array}{l}\text { Composite } \\
\text { Reliability } \\
\text { a }\end{array}$ & $\mathrm{AVE}^{\mathrm{b}}$ \\
\hline \multirow[t]{9}{*}{ Communication } & COM1 & 0.803 & 0.93 & 0.942 & 0.646 \\
\hline & COM2 & 0.828 & & & \\
\hline & COM3 & 0.881 & & & \\
\hline & COM4 & 0.79 & & & \\
\hline & COM5 & 0.89 & & & \\
\hline & COM6 & 0.779 & & & \\
\hline & COM7 & 0.836 & & & \\
\hline & COM8 & 0.624 & & & \\
\hline & COM9 & 0.773 & & & \\
\hline \multirow[t]{6}{*}{ Customer relationship Management } & CUS_REL1 & 0.702 & 0.933 & 0.942 & 0.577 \\
\hline & CUS_REL10 & 0.767 & & & \\
\hline & CUS_REL11 & 0.708 & & & \\
\hline & CUS_REL12 & 0.79 & & & \\
\hline & CUS_REL2 & 0.705 & & & \\
\hline & CUS_REL3 & 0.692 & & & \\
\hline
\end{tabular}




\begin{tabular}{|c|c|c|c|c|c|}
\hline & CUS_REL4 & 0.811 & & & \\
\hline & CUS_REL5 & 0.815 & & & \\
\hline & CUS_REL6 & 0.806 & & & \\
\hline & CUS_REL7 & 0.796 & & & \\
\hline & CUS_REL8 & 0.778 & & & \\
\hline & CUS_REL9 & 0.73 & & & \\
\hline \multirow[t]{13}{*}{ Organisational Performance } & ORG_PER13 & 0.679 & 0.944 & 0.949 & 0.51 \\
\hline & ORG_PER17 & 0.725 & & & \\
\hline & ORG_PER20 & 0.662 & & & \\
\hline & ORG_PER24 & 0.78 & & & \\
\hline & ORG_PER25 & 0.779 & & & \\
\hline & ORG_PER26 & 0.655 & & & \\
\hline & ORG_PER27 & 0.732 & & & \\
\hline & ORG_PER28 & 0.688 & & & \\
\hline & ORG_PER29 & 0.776 & & & \\
\hline & ORG_PER30 & 0.671 & & & \\
\hline & ORG_PER31 & 0.65 & & & \\
\hline & ORG_PER7 & 0.714 & & & \\
\hline & ORG_PER8 & 0.715 & & & \\
\hline
\end{tabular}

a: $\mathrm{CR}=(\Sigma$ factor loading $) 2 /\{(\Sigma$ factor loading $) 2)+\Sigma$ (variance of error $)\}$

$\mathrm{b}: \mathrm{AVE}=\Sigma$ (factor loading) $2 /(\Sigma$ (factor loading) $2+\Sigma$ (variance of error $)\}$

\subsubsection{The Discriminant Validity}

SEM literature refers to discriminant validity as the level of items that can differentiate a construct from other constructs in the model. In this regard, Compeau et al. (1999) stated that the construct items should differ from those of other constructs in the model. The diagonal line of values containing the square root of AVE, along with the constructs correlations are presented in Table 6. The descriminant validity is established by comparing the values of the diagonal line to other diagonal ones and ensuring that they are higher than the latter in their respective columns and rows. Based on the criterion laid down by Fornell and Larcker (1981), the model's discriminant validity is confirmed. 


\section{Macrothink}

Table 6. Correlation and discriminant validity

\begin{tabular}{|l|l|l|l|}
\hline Construct & Communication & $\begin{array}{l}\text { Customer } \\
\text { relationship } \\
\text { Management }\end{array}$ & $\begin{array}{l}\text { Organisational } \\
\text { Performance }\end{array}$ \\
\hline Communication & $\mathbf{0 . 6 4 6}$ & & \\
\hline $\begin{array}{l}\text { Customer relationship } \\
\text { Management }\end{array}$ & 0.26 & $\mathbf{0 . 5 7 7}$ & $\mathbf{0 . 5 1}$ \\
\hline Organisational Performance & 0.39 & 0.44 & \\
\hline
\end{tabular}

\subsection{The Inner Model (Structural Model), and Hypotheses Testing}

Following the confirmation of the construct's validity and reliability, the inner model was examined to test the hypotheses and for this, the Algorithm and Bootstrapping in PLS (See Figure 2 and Table 7) were employed.

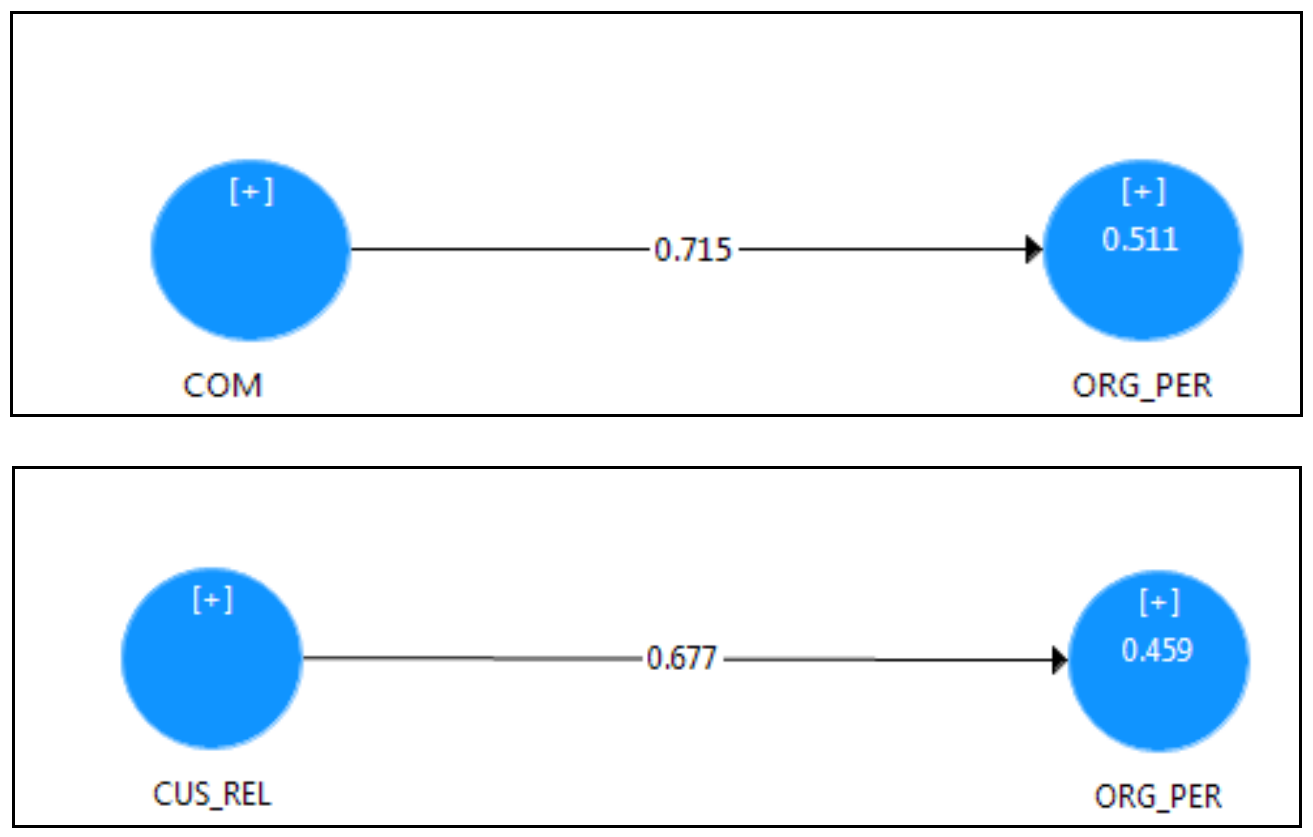

Figure 2. Hypotheses testing results

Table 7. Relationship between communication, customer relationship management and organisational performance

\begin{tabular}{ccccc}
\hline Hypothesis & estimate & t-Value & $\mathrm{P}$ & Supported? \\
\hline $\mathrm{COM} \rightarrow$ ORG_PER & 0.715 & 12.272 & $* * *$ & Supported \\
\hline CUS_REL $\rightarrow$ ORG_PER & 0.677 & 11.038 & $* * *$ & Supported \\
\hline
\end{tabular}

From Figure 2 and Table 7, it is evident that the entire hypotheses were revealed to be positive and significant at the level of significance of 0.01 . Therefore, the hypotheses 
$(\mathrm{H} 1+\mathrm{H} 2)$ proposed in the study are supported.

\section{Discussion of Results}

The results of the study revealed that this hypothesis was accepted at a substantial level. The relationship shows how that the communication variable can influence the organisational performance. Communicating needs to be effective and reliable, otherwise concerns or issues across the hospital would not be addressed or known. Communication is also crucial between employees and patients, any concern or issue that is not communicated across to the relevant managers or departments would affect the organisational performance either negatively or positively.

Collaborative teamwork was identified as a positive influence from the findings, most participants agreed with staff cooperating with each other, and there were good working relationships. The communication between staff is good according to the findings, however this could be argued that as participants were managers they perceive communication to be effective. In support of this view from the literature section, Leonard, Graham, and Bonacum (2004) state that effective communication in the healthcare organisations has been cited as essential for achieving high reliability and quality systems in which a "culture of safety" is fulfilled in hospitals. The hospital process of communication shares information across the departments, this shows how communication has to be good to positively influence the performance of the hospital. Communication is an important factor to be considered in the healthcare sector, cited from the literature section; Payne (2006) argues that communication is the most important aspect of the service delivery as communication among the employees from different departments and also between these employees and patients is vital to delivering service satisfaction because when hospital staff takes the time to answer questions of concern to patients, it can alleviate many feelings of uncertainty (Payne, 2006). In further addressing the importance of communication in the healthcare sector, Cronauer (2013) argues that employees who are working in any hospital should have efficient communication skills, whether communication is between these employees and others from different departments or between the employees and patients. However as the study found the communication statements in the hospital environment was positive; meaning organisational performance in terms of communicating across the hospital is supported.

The results of the study revealed that this hypothesis was accepted at a substantial level. The relationship shows how that the customer relationship management variable can influence the organisational performance. Maintaining a good customer relationship will ensure that hospital can provide the healthcare they need, whilst utilising the facilities that the government is providing. If they cannot provide a good customer relationship then the number of patients using the facility will decrease. The perspective of patient care is based on the information from the middle hospital management about the expectations that patients should expect. The problem is this is a new concept in Saudi Arabia; the introduction of perceived HSQ mediating the relationship has only slightly affected the estimation. Therefore HSQ only marginally changes the relationship between CRM and organisational performance. Essentially this variable challenges customer satisfaction, and this directly influences 
organisational performance.

The importance of research on CRM implementation in organisations was addressed by Walberg et al. (2009) who believed that the utilisation of CRM depends on the resources and capabilities of the organization. The researcher further elaborates that it is highly important for organisations to utilise CRM in their practices and strategies as this would in turn achieve organizational goals together with creating a customer value. The problem is that there seems to be a lack of resource availability in the Saudi healthcare system, if this is the case CRM will be affected. The resources available to provide for patients/customers will not be adequate or suitable for purpose; resulting in migration of patients to other healthcare facilities. Also resource availability is important in affecting CRM; for example some healthcare establishments will be specialised to particular medical fields such as cardiology and neurology. If a hospital lacks the facilities or equipment to carry out specialist operations then their customer database will decrease further. Integrating systems between departments shows effective communication and allows patients to experience a better standard of healthcare service.The fact that the vast majority of the statements were supported shows that Saudi hospitals pertain a good relationship with their patients. This shows that CRM positively influences organisational performance.

\section{Conclusion}

On the whole, this study contributes to the body of knowledge regarding the relationships between communication, customer relationship management and organisational performance among Saudi Arabian hospitals. The sample size comprises of 154 hospitals randomly chosen from 259 government hospitals in Saudi Arabia. The study made use of PLS to examine the relationship between independent variables and dependent variable. Finally, this study revealed that there is a positive and significant association between communication, customer relationship management and organisational performance.

\section{Limitations and Suggestions for Future Research}

Based on the above discussions and results, this research like previous studies, has some limitations. First, this study examined the relationship between communications, customer relationship management and thus, future research can focus on other variables that can improve the level of the companies' performance. Second, this study just explored the direct association between communication, customer relationship management so it is recommended that future research take into account a third variable in order to give consistent results. Finally, this study was applied in the Saudi Arabian context, so future research could consider to examine this relationship in other countries and to make a comparison between Saudi and other countries of the same level.

\section{References}

Alharbi, M. N. (2014). Identifying the Factors That Influence the Quality of Health Care Services in the Public Hospitals in Saudi Arabia. Unpublished Thesis, UUM, Malaysia.

Alharbi, M. N. (2014). Identifying the Factors That Influence the Quality of Health Care 
Services in the Public Hospitals in Saudi Arabia. Unpublished Thesis, UUM, Malaysia.

Almalki, M., Fitzgerald, G., \& Clark, M. (2011). Health care system in Saudi Arabia: an overview. EMHJ, 17(10).

Arora, N. K. (2003). Interacting with cancer patients: "The significant of Physicians' Communication behavior. Social Science \& Medicine, 57, 791-806. https://doi.org/10.1016/S0277-9536(02)00449-5

Bagozzi, R., \& Yi, Y. (1988). On the evaluation of structural equation models. Journal of the Academy of Marketing Science, 16, 74-94. https://doi.org/10.1007/BF02723327

Bansal, M. K. (2004). Optimizing Value and Quality in General Practice of Primary Health Care Sector through Relationship Marketing: A Conceptual Framework. International Journal of Health Care Quality Assurance, 17(4), 180188. https://doi.org/10.1108/09526860410541496

Bitner, M.J., Booms, B.H., \& Tetreault, M.S. (1990). The service encounter: diagnosing favorable and unfavorable incidents. Journal of Marketing, 54, 71-84. https://doi.org/10.2307/1252174

Bolton, R. N. a. D., \& James H. (1991).A Multistage Model of Customers' Assessments of Service Quality and Value. Journal of Consumer Research., 17(4), 375-384. https://doi.org/10.1086/208564

Cheng, P.H., Chen, S.J., Lai, J.S., \& Lai, F. (2008). A collaborative knowledge management process for implementing healthcare enterprise information systems. IEICE Transactions on Information and Systems, E91-D(6), 1664-1672. https://doi.org/10.1093/ietisy/e91-d.6.1664

Chin, J. Henseler, \& H. Wang (Eds.). (1998). Handbook of Partial Least Squares: Concepts, Methods and Applications (pp. 691-711). Heidelberg: Springer.

Cohen, A. R., \& Bradford, D. L. (2005). The influence model: Using reciprocity and exchange to get what you need. Journal of Organizational Excellence, 25(1), 57-80. https://doi.org/10.1002/joe.20080

Cohen, L., Manion, L., \& Morrison, K. (2000). Research Methods in Education (5th edition). London, RoutledgeFalmer. https://doi.org/10.4324/9780203224342

Compeau, D.R., Higgins, C.A., \& Huff, S. (1999). Social cognitive theory and individual reactions to computing technology: a longitudinal study. MIS Quarterly, 23(2), 145-158. https://doi.org/10.2307/249749

Cronauer, C. K. (2013). How physician affective communication skills are related to patient characteristics and outcomes Empathy and self-awareness in the spotlight. Thesis presented at the Faculty of Economics Institute of Work and Organizational Psychology: University of Neuchâtel.

Farid, I. M. F. (2008). Development of a Model for Healthcare Service Quality: An Application to the Private Healthcare Sector in Egypt. DBA Dissertation, Maastricht School 
of Management.

Fornell, C., \& Larcker, D. F. (1981).Evaluating Structural Equation Models with unobservable variables and measurement error. Journal of Marketing Research 18, 39-50. https://doi.org/10.2307/3151312

Friedman, J., \& S. Kelman. (2007). Effort as Investment: Analyzing the Response to Incentives, Working Paper Series rwp07-024, Harvard University, John F. Kennedy School of Government.

Gallagher EB. (2002). Modernization and health reform in Saudi Arabia, Chapter 4. In: Twaddle AC, ed. Health care reform around the world. London, Auburn House, 181-197.

Gawande, AA, Zinner, MJ, Studdert, DM, \& Brennan TA. (2003). Analysis of errors reported by surgeons at three teaching hospitals. Surgery, 133(6), 614-21. https://doi.org/10.1067/msy.2003.169

Gay, L. R., Mills, G. E., \& Airasian, P. (2006). Educational research: Competencies for analysis and applications (8th ed.). Upper Saddle River, NJ: Pearson.

Habidin, N. F., Ali, N., Khaidir, N. A., Shazali, N. A., \& Jusoh, O. (2015). Relationship between Customer Relationship Management, Service Quality Improvement and Organizational Performance in Malaysian Healthcare Industry. International Journal of Innovation and Scientific Research, 14(2), 293-302. ISSN 2351-8014.

Hair, J. F., Black, W. C., Babin, B. J., \& Anderson, R. E. (2010). Multivariate data analysis (7th ed.). Upper Saddle River, New Jersey: Prentice Hall.

Irving, P., \& Dickson, D. (2004). Empathy: towards a conceptual framework for health professionals. International Journal of Health Care Quality Assurance, 17(4/5), 212-20. https://doi.org/10.1108/09526860410541531

Leonard M, Graham S, \& Bonacum D. (2004). The human factor: the critical importance of effective teamwork and communication in providing safe care. QualSaf Health Care, 13(1), 85-90. https://doi.org/10.1136/qshc.2004.010033

Pallant, J. (2007). SPSS: A Step by Step guide to Data Analysis Using SPSS for Windows (Version 15) (3rd ed.). Crows Nest, NSW: Allen \& Unwin.

Parasuraman, A., Zeithaml, V.A., \& Berry, L.L. (1994). Reassessment of expectations as acomparison standard on measuring service quality: implications for further research. Journal of Marketing, 58(1), January, 111-24. https://doi.org/10.2307/1252255

Payne, A. (2006). Handbook of CRM: Achieving Excellence in Customer Management, Amsterdam: Butterworth.

Pickton, D., \& Broderick A. (2001). Integrated Marketing Communications, Pearson Education, Barcelona.

Richard, L.S., \& Ronald M.E. (2008). Lessons from Theory \& Research on Clinician-Patient 


\section{Macrothink}

Journal of Management Research

ISSN 1941-899X

2017, Vol. 9, No. 4

Communication In: Karen G., Barbara K.R, K.Viswanth (eds.) Health Behavior and Health Education; Theory, Research, and Practice, 4th edition, (11),236-269 JOSSEY-BASS.

Sekaran, U. (2003). Research Methods for Business: A Skill Building Approach, John Wiley $\&$ Sons.

Supratiko, G., M. E. Wirth, E. Achadi, S. Cohen, \& C. Ronsmans. (2002). A District-Based Audit of the Causes and Circumstances of Maternal Death in South Kalimantan. Indonesia. Bulletin of the World Health Organization, 228-234.

Walberg, O., Strandberg, C., Sundberg, H., \& Sandberg, K. W. (2009). Trends, Topic and Under Researched Areas in CRM Research: A Literature Review. International Journal of Public Information System, 2(3), 191-208.

Yina, W. (2010). Application of Customer Relationship Management in Health Care. Multimedia and Information Technology (MMIT), 1, 52-55, 10.1109/MMIT. https://doi.org/10.1109/MMIT.2010.31

Zablah, A. R., Bellenger, D. N., \& Johnston, W. J. (2004). Customer Relationship Management Implementation Gaps. Journal of Personal Selling and Sales Management, xxiv(4), 279-95.

Zineldin, M. (2006a). The Royalty of Loyalty: CRM, Quality and Retention. Journal of Consumer Marketing, 23(7), 430-437. https://doi.org/10.1108/07363760610712975 